
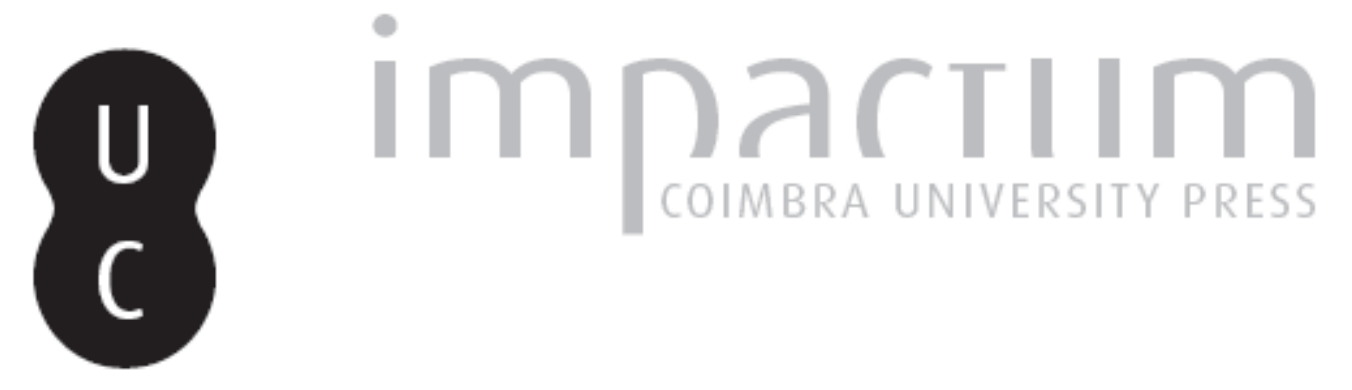

\title{
As despesas da reconstrução da fortaleza de Diu em 1546-1547
}

Autor(es): Jesus, Roger Lee de

Publicado por: Centro de História da Sociedade e da Cultura

URL persistente:

URI:http://hdl.handle.net/10316.2/39431

DOI:

DOI:http://dx.doi.org/10.14195/1645-2259_12_10

Accessed : $\quad$ 26-Apr-2023 11:37:24

A navegação consulta e descarregamento dos títulos inseridos nas Bibliotecas Digitais UC Digitalis, UC Pombalina e UC Impactum, pressupõem a aceitação plena e sem reservas dos Termos e Condições de Uso destas Bibliotecas Digitais, disponíveis em https://digitalis.uc.pt/pt-pt/termos.

Conforme exposto nos referidos Termos e Condições de Uso, o descarregamento de títulos de acesso restrito requer uma licença válida de autorização devendo o utilizador aceder ao(s) documento(s) a partir de um endereço de IP da instituição detentora da supramencionada licença.

Ao utilizador é apenas permitido o descarregamento para uso pessoal, pelo que o emprego do(s) título(s) descarregado(s) para outro fim, designadamente comercial, carece de autorização do respetivo autor ou editor da obra.

Na medida em que todas as obras da UC Digitalis se encontram protegidas pelo Código do Direito de Autor e Direitos Conexos e demais legislação aplicável, toda a cópia, parcial ou total, deste documento, nos casos em que é legalmente admitida, deverá conter ou fazer-se acompanhar por este aviso.

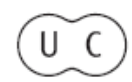


evista de História da Sociedade e da Cultura

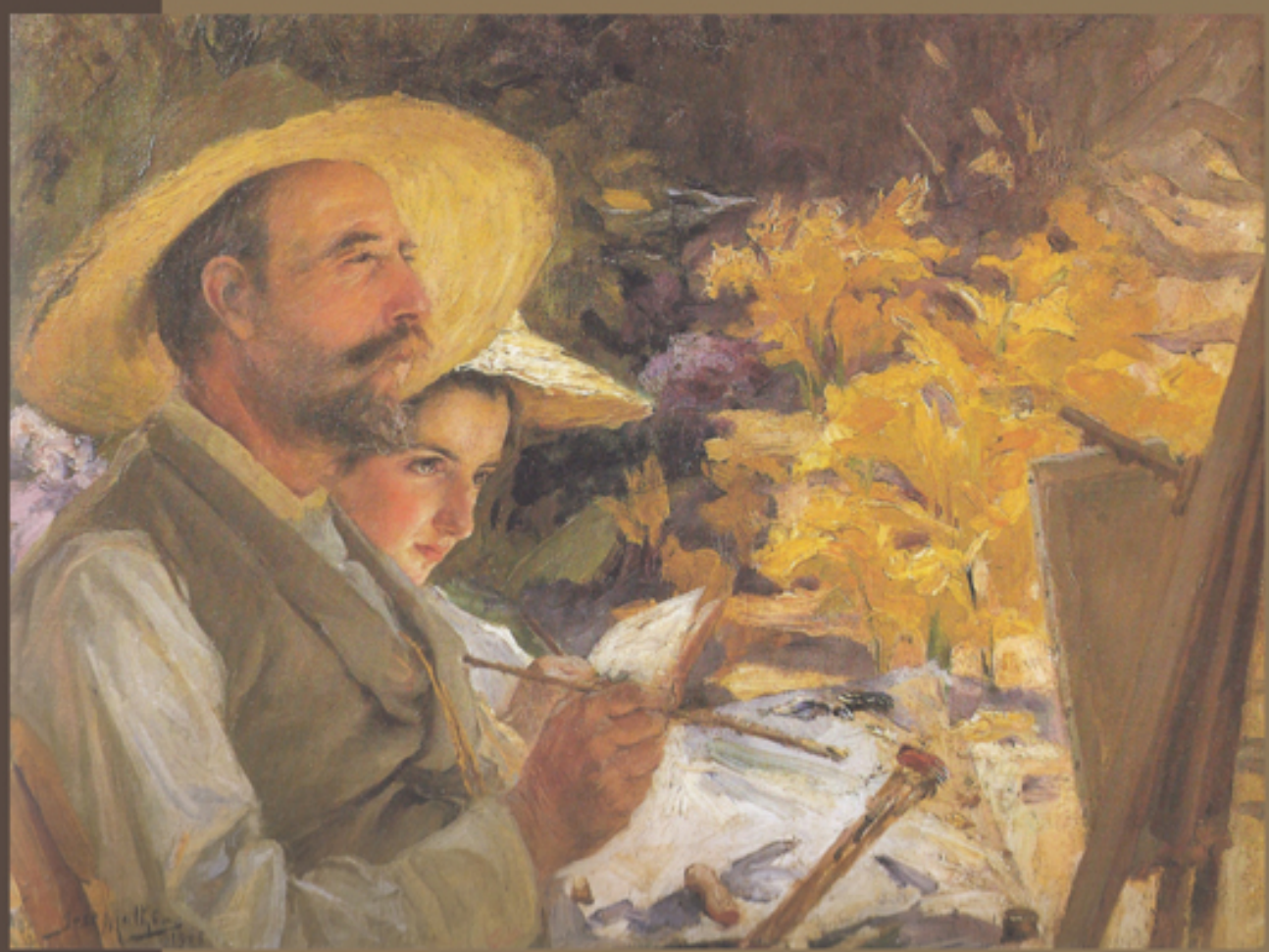

Centro de História da Sociedade e da Cultura Universidade de Coimbra 


\title{
As despesas da reconstrução da fortaleza de Diu em 1546-1547
}

\author{
Roger Lee de Jesus \\ Doutorando do $3^{\circ}$ Ciclo em Altos Estudos em História - Época Moderna \\ Universidade de Coimbra \\ rogerlee.pj@gmail.com \\ Texto recebido em /Text submitted on: 28/02/2012 \\ Texto aprovado em /Text approved on: 29/10/2012
}

\section{Resumo/Abstract:}

Entre Abril e Novembro de 1546, a fortaleza portuguesa de Diu sofreu um forte cerco às mãos do sultanato do Guzerate, oito anos após ter sido cercada pela primeira vez pelas mesmas forças apoiadas por um contingente otomano. A artilharia inimiga arrasou sucessivamente as muralhas, deixando o forte num estado tal que impedia o seu simples restauro. A reconstrução desta fortaleza (conforme o novo tipo de fortificação abaluartada) estendeu-se de Novembro de 1546 a Abril do ano seguinte, criando o bastião que finalmente firmaria a presença portuguesa na região. Este artigo pretende analisar, num primeiro momento, as despesas efectuadas com as obras, como sejam os pagamentos dos mantimentos e do serviço levado a cabo por pedreiros, cabouqueiros, carpinteiros e outros trabalhadores contratados pela Coroa para esse fim, e, numa segunda fase, os meios usados para financiar estes custos. Baseamos o nosso discurso não apenas nas diversas crónicas respeitantes a esse período, mas sobretudo nos registos das despesas efectuadas conservados no Códice 51-VII-19 da Biblioteca da Ajuda, contendo certidões, listas de pagamentos e, não menos importante, o Caderno das despesas que se fizeram em obras na fortaleza de Diu, datado de Julho de 1547 e aqui publicado na íntegra. Este estudo pretende demonstrar que os custos tidos em conta não pesaram na estrutura financeira do Estado da Índia.

The Portuguese fortress of Diu was besieged by the sultanate of Gujarat between April and November 1546, eight years after the first siege by this same forces helped with an Ottoman reinforcement. The enemy artillery swept successively the walls, leaving the fort in need of repair. The reconstruction of the fortress (as the new type of trace italienne) lasted from November 1546 to April of the following year, creating a structure that finally secured the Portuguese presence in the region. This article has two aims: firstly, the analysis of the costs of the works, such as payments of the supplies and the service conducted by masons, hackers, carpenters and other workers hired by the Crown, and secondly an assessment of the means used to finance these costs. The discussion is based not only on the various chronicles relating to that period, but especially in a list of expenses in the Codex 51-VII-19 of the Biblioteca da Ajuda, containing certificates, lists of payments and, not least, the Caderno das

* Este trabalho constitui uma versão alargada da comunicação apresentada ao XXXI Encontro da Associação Portuguesa de História Económica e Social, realizado em Coimbra, em Novembro de 2011. A versão final deste artigo é fruto das sugestões e comentários da Ana Rita Rocha e Marta Santos, a quem agradecemos. A nossa gratidão vai também para a Prof. Doutora Maria do Rosário Morujão, pelo auxílio prestado na transcrição do documento que ora se publica. 
despesas que se fizeram em obras na fortaleza de Diu, dated July 1547 and here published. A final analysis shows that the expenses were not significant in the whole of the budget of the Portuguese State of India. The paper concludes that the expenditures were not significant on the whole of the financial structure of the Portuguese State of India.

Palavras chave/Keywords:

Diu; Guzerate; História Económica e Financeira; Estado da Índia; D. João de Castro.

Diu; Gujarat; Financial History; Portuguese State of India; D. João de Castro. 
Vereis a inexpugnábil Dio forte, Que dous cercos terá, dos vossos sendo.

Ali se mostrará seu preço e sorte, Feitos de armas grandissimos fazendo

Luís de Camões, Os Lusíadas, canto II, estrofe 50.

Assim referia Camões os dois cercos de Diu (1538 e 1546), feitos militares incontornáveis da Índia portuguesa quinhentista. O segundo cerco, ocorrido durante a governação de D. João de Castro e pelas forças do sultanato do Guzerate, durou de Abril a Novembro de 1546 e revelou-se devastador: nas palavras do Governador, «[...] os mouros tinhão entulhado as cavas de maneira que nam havia sinal [delas], nem poder se saber onde forão, e os muros derribados até o fundamento, e os baluartes tomados, e elles postos em sima com muitas estancias de artilharia com que atiravão as cazas da fortaleza» ${ }^{1}$. Na realidade, «[...] o proprio capitam e moradores della me não sabiam dizer aonde estavão os baluartes e por onde corrião os muros e o lugar onde fazia a cava, tamanhas montanhas de pedra e terra tinhão lançado em todas estas partes, de maneira que parecia impossível e hum trabalho insuportável poder tirar esta pedra e tornar a erguer a fortaleza polo lugar por onde primeiro estava $\rangle^{2}$. Só restava ao Governador erguer uma nova fortaleza.

Procuraremos ao longo deste artigo analisar as despesas da reconstrução da fortaleza de Diu, que foi levada a cabo entre Novembro de 1546 e Abril de 1547. Partindo da documentação oficial, emanada da administração central do Estado da Índia ${ }^{3}$, basearemos o nosso trabalho nas diversas certidões das feitorias de Goa, Chaul, Baçaim e Diu, particularmente na «Lembrança de pagamento aos oficiais que trabalharam na fortaleza de Diu», no «Trelado das ferias que foram pagas à gente da terra guzerates, carpinteiros, pedreiros, cabouqueiros, bigarins e mulheres que trabalharam nas obras desta fortaleza», e principalmente no Caderno das despesas que se fizeram no fazimento da fortaleza de Diu que o senhor governador Dom

1 Carta de D. João de Castro para D. João III, datada de 16 de Dezembro de 1546 in CORTESÃO, Armando e ALBUQUERQUE, Luís - Obras Completas de D. João de Castro. Coimbra: Academia Internacional da Cultura Portuguesa, 1976, vol. III, p. 302.

2 Ob. cit., p. 307.

3 Existente actualmente na Biblioteca da Ajuda (Lisboa), Códice 51-VII-19. 
João de Castro fez de novo - documento que publicamos adiante na íntegra. Teixeira de Aragão referira já a existência deste documento na sua magna obra sobre a numismática portuguesa ${ }^{4}$, destacando-se ainda Magalhães Godinho que chamara a atenção para este Caderno e para as suas certidões, afirmando ser um «bon exemple d'enregistrement de dépenses faites avec des travaux publics bien determinés $\rangle^{5}$. No entanto, o apelo não vingou e a documentação continua inédita - pelo que a nossa pesquisa revelou -, não obstante oferecer múltiplas formas de análise do foro económico e financeiro.

1. Sobre Diu, recordemos que este porto, localizado na costa do Guzerate e pertencente a este sultanato (também referido como sendo de Cambaia, pela importância económica desta cidade), situava-se geograficamente na confluência de diversas rotas marítimas: do Mar Roxo, do Golfo Pérsico, da Costa do Malabar, da Costa Oriental de África, do Golfo de Bengala e do Sudeste Asiático. Lembremos a já famosa referência de Tomé Pires, quando afirma que «primcipallmemte Cambaia lamca dous braços: com ho dereito aferra Adem e com o outro Malaqua» ${ }^{6}$. Quanto à interdependência dos dois entrepostos, o mesmo autor dirá: «nom pode viver Malaca sem Cambaya nem Cambaya sem Malaqua» ${ }^{7}$.

Após diversas tentativas de cedência e conquista, Diu foi entregue aos portugueses a 25 de Outubro de 1535, em troca de ajuda militar ao sultão, que se encontrava em árdua guerra contra o Grão-Mogol. Não contente com esta cedência, o sultão Bahadur acabou por tentar retomar a cidade, sendo morto numa contenda (pouco esclarecida) após um encontro com o governador Nuno da Cunha, em 1537. Tal processo desembocaria no primeiro cerco à cidade, no ano seguinte, marcado pela participação de um contingente turco-

4 Descripção Geral e Historica das Moedas Cunhadas em Nome dos Reis, Regentes e Governadores de Portugal. Lisboa: Imprensa Nacional, 1880, v. III, p. 135, referindo somente um «manuscrito contemporâneo existente na biblioteca da Ajuda».

5 GODINHO, Vitorino Magalhães - Les Finances de l'État Portugais des Indes Orientales (1517-1635). (Matériaux pour uns Étude Structurale et Conjoncturelle). Paris: Fundação Calouste Gulbenkian/Centro Cultural Português, 1982, p. 13.

6 CORTESÃO, Armando (leitura e notas) - A Suma Oriental de Tomé Pires e o Livro de Francisco Rodrigues, Coimbra: Por Ordem da Universidade, 1978, p. 199.

7 Ob. cit., p. 202. 
-otomano. Não obstante a resistência portuguesa e a consequente derrota da coligação guzerate-otomana, marcadas por um tratado de paz de 1539, a ameaça de Cambaia voltou-se a fazer sentir na década seguinte.

O segundo cerco surge por acção deliberada do rei de Cambaia, Mahmud III, com o objectivo de recuperar a cidade e o comércio que os portugueses controlavam, e o início do assédio pertenceu a Coge Sofar, senhor de Surrate. Começando as hostilidades a 22 de Abril, os constantes bombardeamentos e as sucessivas vagas de assalto quase que arrasaram e conquistaram a fortaleza. Os frequentes reforços de mantimentos e de homens de armas, enviados pelo Governador D. João de Castro, entre os quais se incluem os próprios filhos (D. Fernando e D. Álvaro, em momentos separados, vindo o primeiro a falecer na explosão do baluarte S. João), foram vitais para a resistência. Após seis longos meses e meio de cerco, a armada de socorro, organizada em Goa pelo Governador, chega a Diu em inícios de Novembro, enfrentando em batalha as forças inimigas a 10 de Novembro, véspera de S. Martinho, e culminando numa estrondosa vitória das forças portuguesas ${ }^{8}$.

Necessitando de uma profunda restruturação, a reconstrução da fortaleza seguiu o novo modelo de fortificação abaluartada ${ }^{9}$. Explicitemos a forma que tomou o novo forte, tomando por informador Leonardo Nunes: «tem tres grandes baluartes feitos em triangullo, alamborados com suas casas mates que joguam muyto grosas peças d'artelharia, que saem d'antre as orilhas dos baluartes e o muro, em todollos baluartes de hua parte e da outra que se nam podem çeguar $\rangle^{10}$. D. João de Castro afirmava ainda que a construção se destacaria pela abertura de um fosso, frente à nova muralha «[...] porque entam ficara Dio com duas cavas e duas muralhas, remendiandose os muros velhos de maneira que fiquem em terraplano sobre a cava antigua» ${ }^{11}$. A fortaleza que hoje perdura em Diu remonta às obras de 1546-1547.

8 Sobre este cerco veja-se a nossa dissertação de mestrado: JESUS, Roger Lee Pessoa de - O Segundo Cerco de Diu (1546). Estudo de História Política e Militar. Coimbra: FLUC, 2012.

9 Segundo o cronista Gaspar Correia, «pera ofender e defender»-Lendas da Índia. Porto: Lello \& Irmão Editores, 1975, vol. IV, p. 583. Doravante esta obra será somente designada como Lendas da Índia, dizendo respeito ao quarto volume

${ }^{10}$ NUNES, Leonardo - Crónica de Dom João de Castro. Cambridge: Harvard University Press, 1936, p. 138.

${ }^{11}$ Carta de D. João de Castro para D. João III..., cit., p. 307. 
A existência de duas muralhas (a primeira abaluartada, seguida de uma singela cortina de pedra), com um impressionante fosso frente aos baluartes (aberto posteriormente, em 1550), é elemento importante da construção estratégica da fortaleza de Diu, encravando definitivamente o sistema defensivo português na ilha e assegurando o domínio militar na região ${ }^{12}$.

2. A coordenação geral da obra ficou a cargo de Mestre Francisco Pires, homem que chegara do Reino nesse ano com o objectivo de erguer a fortaleza de Moçambique ${ }^{13}$. O mau tempo e a necessidade de chegar ao Malabar levaram a que a sua nau, capitaneada por Lourenço Pires de Távora, optasse por passar ao largo da ilha de S. Lourenço, entrando posteriormente na armada de socorro a Diu ${ }^{14}$. Quanto à figura deste técnico, salientemos os largos elogios feitos por D. João de Castro sobre a sua perícia, afirmando em carta ao filho que «não temos qua melhor cousa» ${ }^{15}$. Quanto ao traçado da obra, não sabemos se o terá decidido só por si ou debatido com as principais figuras de comando, pois já em Maio de 1546 (em pleno cerco), o capitão de Diu, D. João de Mascarenhas, afirmava ao Governador que pensara em reconverter a fortaleza em «hũa obra que Vitruvio não pudera mays imaginar», salientando que o faria com pouco trabalho e pequeno gasto $^{16}$. Além de Francisco Pires, destacam-se na direcção dos trabalhos Mestre Afonso Madeira (também mestre de obras ${ }^{17}$ ), Mestro Pero (mestre das ferrarias) e Mestre Francisco de Resende (mestre dos carpinteiros).

${ }^{12}$ Veja-se a recente entrada sobre Diu na obra de MATTOSO, José (dir.) - Património de Origem Portuguesa no Mundo. Arquitectura e Urbanismo, vol. III: ROSSA, Walter (coord.) - Ásia, Oceania. Lisboa: Fundação Calouste Gulbenkian, 2010, p. 121-125.

${ }^{13}$ Sousa Viterbo adianta alguns elementos sobre este especialista na arquitectura militar em Dicionário histórico e documental dos arquitectos, engenheiros e construtores portugueses. Lisboa: INCM, 1988, vol. II - H/R, p. 299-303.

${ }^{14}$ Lendas da Índia, p. 581.

${ }^{15}$ Carta de D. João de Castro para D. Álvaro de Castro, datada de 13 de Agosto de 1547 in Obras Completas de D. João de Castro..., cit., p. 434.

${ }^{16}$ Carta de D. João de Mascarenhas a D. João de Castro, datada de 5 de Maio de 1546 Arquivo Nacional da Torre do Tombo, Lisboa (doravante citado por ANTT), Colecção São Lourenço, Livro V, fl. 157r., publicada em BAIÃO, António - História quinhentista (inédita) ..., cit., p. 154.

${ }^{17}$ Talvez servindo como vedor das obras - sobre este cargo cf. TEIXEIRA, André Fortalezas do Estado Português da Índia, Arquitectura Militar na Construção do Império de D. Manuel I. Lisboa: Tribuna da História, 2008, p. 170-171. 
Entre os trabalhadores comuns encontramos pedreiros, cabouqueiros, ferreiros, carpinteiros, mocadões (chefes de tripulação, capatazes), bigarins (mariolas, homens contratados para servir e carregar), boys (homens que exercem misteres baixos, como os de carregador e aguadeiro) e mulheres (não se especificando o seu papel nas obras). Do Caderno das Despesas contamos cerca de 1400 trabalhadores, na sua maioria gente da terra proveniente de Goa (cerca de mil ${ }^{18}$. Além destes trabalhadores contamos ainda os jornaleiros guzerates contratados: cerca de 3900 ao final de dezanove semanas de trabalho. Não esqueçamos a presença de soldados e fidalgos, também empenhados nas obras, que segundo Leonardo Nunes seriam mais de trezentos ${ }^{19}$. Veja-se o exemplo de Miguel Rodrigues (que fora juntamente com D. Álvaro de Castro na armada de socorro a Diu, tendo sido ferido na batalha do dia 10 de Novembro), que em carta a D. João III o informa de que o governador lhe dera mercê do «cuidado dos fornos da cal que se faz pera esta fortaleza» ${ }^{20}$.

Quanto à organização do trabalho, as fontes apenas nos revelam alguns elementos. Segundo Gaspar Correia, o governador nomeou vedores e mandadores, definindo as suas tarefas e respectivos dias, estando ainda estes sob alçada de outros capatazes, de forma a não faltar nada na obra ${ }^{21}$. Já o seu neto, Fernando de Castro, na biografia que dedicou ao avô, diz-nos que D. João de Castro repartiu em terços a gente que tinha «[...] para que o trabalho se repartisse por todos igualmente sem nenhuma maneira de excepção» ${ }^{22}$. Os dois escritos parecem complementar-se, apresentando um sistema bem organizado, e vigiado não somente pelo

${ }^{18}$ D. Jerónimo de Noronha, capitão de Baçaim alertara o governador para a falta de pedreiros e cabouqueiros na sua fortaleza, sendo necessário trazê-los de Goa-Colecção de São Lourenço, vol. III. Lisboa: IICT, 1983, p. 167. A elevada taxa de mortalidade existente na ilha, aquando das obras, é registada por Leonardo Nunes na sua crónica (Crónica de Dom João de Castro, cit., p. 145-146) e perceptível na gradual diminuição dos trabalhadores em alguns registos do Caderno das Despesas, nomeadamente na prorrogação dos pagamentos.

${ }^{19}$ NUNES, Leonardo - Crónica de Dom João de Castro, cit., p. 138.

${ }^{20}$ Carta de Miguel Rodrigues para D. João III, datada de 24 de Novembro de 1546 ANTT, Corpo Cronológico, Parte 1. ${ }^{\text {a }}$, Maço 78, N. ${ }^{\circ}$ 94, publicado por António Baião em História Quinhentista (inédita) ..., cit., p. 240.

${ }^{21}$ Lendas da Índia, p. 582.

${ }^{22}$ CASTRO, D. Fernando de - Crónica do Vice-Rei D. João de Castro. Transcrição e notas de Luís de Albuquerque e Teresa Travassos Cortez da Cunha Matos. Tomar: Escola Superior de Tecnologia de Tomar, 1995, p. 341. 
mestre-de-obras principal (Francisco Pires) como também pelo próprio governador, que se encontrava diariamente nas obras, desde o romper da alva até à noite, «[...] vestido num pellote de chamalote preto, e com hum sombreiro de Purtugual na cabeça, e huas botas pretas calçadas, e sua espada cimgida, todo cheo de caal» ${ }^{23}$. Simão Botelho, vedor da fazenda (autor do Tombo do Estado da Índia de 1554), terá sido responsável pela supervisão financeira das obras, indicando ao monarca os seus serviços, referindo a «[...] pouqa despeza [que] se fez nela, porque coria tudo por minha mão, e em meu poder estava o dinheiro, e presente mym se fazião todas as despesas $\rangle^{24}$.

Da vintena de registos de pagamentos dos trabalhadores existentes no Caderno das Despesas, a grande maioria indica-nos uma periodicidade de remuneração bimensal, existindo obviamente exemplos de prorrogação de tempo de trabalho. Veja-se o exemplo de cerca de 20 pedreiros de Chaul, pagos pelo tempo de um mês (de 7 de Novembro a 7 de Dezembro) a 43 pardaus de tangas, seguindo-se o adiamento por dois meses, de 7 de Dezembro a 7 de Fevereiro, por 80 pardaus de tangas ${ }^{25}$. No que diz respeito aos trabalhadores guzerates, as contas foram feitas semanalmente, somando assim dezanove semanas de trabalho, de 29 de Novembro - data do início das obras - a 11 de Abril. Neste último caso, o «Trelado das fereas que ho feitor Antonio Gill feitor de Dio pagou a jemte da tera guzarates» ${ }^{26}$ segue escrupulosamente todas este tempo, apontando os gastos monetários e de arroz tidos com estes homens e mulheres.

A moeda mais utilizada nos registos do Caderno é o pardau de tanga (valendo cinco tangas o pardau), não obstante algumas referências a pardaus de ouro. A diferença entre uma e outra cinge-se ao metal utilizado - a prata para a primeira e o ouro para a segunda ${ }^{27}$. Encontramos ainda referência a

${ }^{23}$ NUNES, Leonardo - Crónica de Dom João de Castro, cit., p. 139.

${ }^{24}$ Carta de Simão Botelho para D. João III, datada de 24 de Dezembro de 1548 - ANTT, Corpo Cronológico, Parte 1. a, Maço 81, N. ${ }^{\circ}$ 124, publicado por António Baião - História Quinhentista (inédita)..., cit., p. 266.

${ }^{25}$ Caderno das Despesas: fls. 238v e 239r.

${ }^{26}$ Trelado, fl. 262r.

${ }^{27}$ Da leitura do Livro dos pesos da Yndia, e assy das medidas e mohedas, de 1554 (fonte fundamental para a conversão de medidas utilizadas à época), podemos assim afirmar que o pardau de tanga equivaleria a cerca de 300 reais e o de ouro a 360. Cf. «O Livro dos Pesos, Medidas e Moedas, por Antonio Nunes» in FELNER, Rodrigo José de Lima-Subsídios para a História da Índia Portuguesa. Lisboa: Typografia da Academia Real das Sciencias, 1868, 
xerafins, moeda também de ouro, no que toca a alguns pagamentos de Chaul e que valeria o mesmo que o pardau de tanga ${ }^{28}$.

Dito isto, analisemos os montantes pagos a cada tipo de trabalhadores. Procuremos averiguar a diferença salarial quanto à natureza do trabalho (entre um pedreiro e um bigarim, por exemplo) ou à proveniência de quem o fazia (vindo de Goa ou de Chaul).

Salários mensais aproximados segundo o Caderno das Despesas

\begin{tabular}{|c|c|c|c|c|c|c|}
\hline \multirow[b]{3}{*}{ Cabouqueiros } & \multicolumn{6}{|c|}{ Proveniência dos trabalhadores } \\
\hline & \multicolumn{2}{|c|}{$\mathrm{Goa}^{29}$} & \multicolumn{2}{|c|}{ Chaul $^{30}$} & \multicolumn{2}{|c|}{ Baçaim $^{31}$} \\
\hline & $2 \mathrm{pt}$ & $600 \mathrm{rs}$ & $2 \mathrm{pt}$ & $600 \mathrm{rs}$ & & \\
\hline Pedreiros & $2 \mathrm{pt}$ & 600rs & $3 \mathrm{pt}$ & 900rs & & \\
\hline Mocadões & $3 p t$ & 900rs & $3 / 4 \mathrm{pt}$ & 900/1200rs & & \\
\hline Carpinteiros & $2 \mathrm{pt}$ & 600rs & & & & \\
\hline Ferreiros & $5 t$ & $300 \mathrm{rs}$ & & & & \\
\hline $\begin{array}{c}\text { Pedreiros } \\
\text { Portugueses }\end{array}$ & $60 v$ & 1080rs & & & & \\
\hline Bigarins & $3,75 \mathrm{t}$ & $225 \mathrm{rs}$ & $1 / 2 \mathrm{pt}$ & $300 / 600 \mathrm{rs}$ & $1 \mathrm{pt}$ & $300 \mathrm{rs}$ \\
\hline
\end{tabular}

$\mathrm{pt}=$ pardaus de tanga, $\mathrm{t}=$ tangas, $\mathrm{v}=$ vinténs, $\mathrm{rs}=$ reais $^{32}$

Notamos assim que não existe uma diferença salarial substancial quanto à proveniência dos trabalhadores indígenas, nem quanto à tarefa por eles exercida. Pedreiros, cabouqueiros e carpinteiros receberiam aproximadamente o mesmo (dois pardaus de tanga por mês), sendo os bigarins menos bem pagos pelo seu trabalho menor.

p. 64. Passaremos a designar esta obra apenas por Livros dos Pesos da Yndia. Magalhães Godinho indica-nos ainda que a tanga pesaria cerca de 4.4 gramas de prata, o que levaria o pardau de tanga para aproximadamente 26 gramas - GODINHO, Vitorino Magalhães Os Descobrimentos e a Economia Mundial. Lisboa: Editorial Presença, 1991, vol. I, p. 261.

${ }^{28}$ Uma certidão de pagamento de Chaul refere um pagamento efectuado em xerafins, sendo que o Caderno das Despesas converterá esse mesmo montante em pardaus de tanga, com idêntico valor - cf. Certidão de Chaul, fl. 252v e Caderno de Despesas, fl. 241r.

${ }^{29}$ Cf. Caderno das despesas, fl. 235v, 236r e 242v.

${ }^{30}$ Idem, fl. 238v, 239v, 240r e v.

${ }^{31}$ Idem, fl. $241 \mathrm{v}$.

${ }^{32}$ Tomou-se em conta que 1 pardau de tanga $=5$ tangas / 300 reais; 1 vintém (não confundir com o vintém de reais) $=18$ reais. Cf. Livros dos Pesos da Yndia, p. 62 e 63 . 
Acerca dos homens e mulheres guzerates que trabalhavam nas obras, engrossando as fileiras a cada semana, encontramos uma certa dificuldade em estabelecer um salário mensal visto que o «Trelado das ferias que foram pagas...» está organizado semanalmente. No entanto, estimamos que andasse por volta de uma tanga por mês, claramente inferior a qualquer montante mencionado anteriormente.

Já os oficiais (mestres de obras) receberiam uma soma superior, graças ao cargo e posição ocupados. A documentação não refere os seus salários, mas tão somente os prémios concedidos no final da obra «pelo muito trabalho que tinhão» ${ }^{33}$ : a Francisco Pires e Afonso Madeira dez pardaus de ouro por mês a cada um, a Mestre Pero 2 pardaus e meio de ouro por mês, e dois pardaus de tanga a Francisco de Resende ${ }^{34}$.

As fontes analisadas oferecem-nos ainda um conjunto de informações quanto às provisões dos trabalhadores e respectivos preços. A alimentação centrava-se no arroz, no pescado, na manteiga e ainda no biscoito no caso dos homens em viagem de Goa para Diu. No entanto, as quantidades não estão todas estipuladas, excepção feita para a manteiga (cerca de um quartilho por $\mathrm{dia}^{35}$ ) e para os guzerates contratados (que recebiam duas medidas de arroz diárias cada um, ou seja, cerca de um quilo ${ }^{36}$ ). Quanto às rações consumidas, na armada de socorro vinda de Goa, durante um mês, 72 pedreiros e cabouqueiros cristãos (da terra) recebiam aproximadamente 200 gramas de biscoito como ração diária; 145 pedreiros e cabouqueiros gentios quase um quilo de arroz por dia (900 gramas); 12 carpinteiros cristãos $160 \mathrm{~g}$ de biscoito e $610 \mathrm{~g}$ de arroz; oito moços ferreiros contavam com cerca de $700 \mathrm{~g}$ de arroz diários ${ }^{37}$. Já em Diu e durante os trabalhos, uma das únicas informações passíveis de ser quantificadas é a quantidade de arroz diária dada a cerca de 130 pedreiros e cabouqueiros, que rondaria as $700 \mathrm{~g}^{38}$. Quanto aos preços observamos uma nítida diferença entre o de arroz

${ }^{33}$ Idem, fl. $243 \mathrm{r}$.

${ }^{34}$ Idem, fl. 243r/v.

${ }^{35}$ Idem, fl. 236v.

${ }^{36}$ Trelado, fl. 266r, sendo que uma medida equivaleria a $0.501 \mathrm{Kg}$, conforme o Livro dos Pesos da Ymdia, p. 58.

${ }^{37}$ Cf. Caderno das Despesas, fls. 235v e 236r, e os dados do Livro dos Pesos da Ymdia, p. 58 .

${ }^{38}$ Idem, fl. 236v. 
proveniente de Goa (variando entre 18 e 22 tangas o candil), de Baçaim ( 7 tangas por candil) e de Diu ( 5 tangas pela mesma medida $)^{39}$.

Dos muitos registos que o Caderno das Despesas contém, falta-nos observar algumas despesas variadas, nomeadamente no que diz respeito a material necessário para a construção, designadamente a cal, trazida de Goa e de Baçaim. Da primeira cidade foram enviados 173 moios (por 116 pardaus) e da segunda 4520 candis, em 27 embarcações (por 693 pardaus) ${ }^{40}$, o que corresponde, respectivamente, a cerca de 147 toneladas e a 100 toneladas ${ }^{41}$. Aludimos ainda a cerca de 5000 cestos utilizados para diversos fins (ascendendo a 100 pardaus de tanga) ${ }^{42}$, ferramentas gastas e roubadas ao longo dos cinco meses de trabalho no valor de 100 pardaus de tanga, e ainda lenha enviada de Chaul, necessária para os fornos da cal (no montante de 106 pardaus e 218 tangas).

Fora isto, as fontes são explícitas quanto à proveniência do material de construção utilizado: a pedra provinha das casas da cidade (que voluntariamente destruíam ${ }^{43}$ ), bem como a madeira para os fornos da cal. Leonardo Nunes diz-nos que os soldados «[...] acarretavam em carretas (onde eles serviam de bois) as grandes lageas e pedras das mesquitas pera as bombardeyras e portais da fortaleza» ${ }^{44}$. D. João de Castro conseguiu, portanto, erguer a nova fortaleza com material já existente na ilha de Diu, e em parte graças ao arraial inimigo que tinha o material necessário, aproveitando-se também a «[...] pedra da parede da contenda» ${ }^{45}$ (a muralha guzerate construída frente à fortaleza). O impacto urbanístico na cidade foi tremendo - «tudo veo ao chão» ${ }^{46}$, nas palavras de Gaspar Correia - contando

${ }^{39} \mathrm{Idem}$, fl. $235 \mathrm{v}, 236 \mathrm{r} / \mathrm{v}$. É-nos ainda dito que o quintal de biscoitos valia 900 reais e a canada de manteiga 1 tanga.

${ }^{40}$ Cf. idem, fls. $242 \mathrm{r} / \mathrm{v}$ e $243 \mathrm{v}$.

${ }^{41}$ Tomámos em conta que um moio equivale a cerca de $850 \mathrm{Kg}$, conforme o artigo de A. H. de Oliveira Marques - «Pesos e Medidas», Dicionário de História de Portugal (dir. Joel Serrão). Porto: Livraria, Figueirinhas, 2002 (reimpressão), vol. V, p. 71; e que um candil equivale a cerca de $220 \mathrm{Kg}$, conforme o Livro dos Pesos da Ymdia, p. 48.

${ }^{42}$ Idem, fl. $242 \mathrm{v}$.

${ }^{43}$ Lendas da Índia, p. 582.

${ }^{44}$ NUNES, Leonardo - Crónica de Dom João de Castro, cit., p. 139.

${ }^{45}$ Cf. COUTO, Diogo do - Da Ásia. Lisboa: Na Regia Officina Typografica, 1781, Década VI, Parte I, p. 304.

${ }^{46}$ Lendas da Índia, p. 582. 
também com os moradores da fortaleza que recolhiam «genellas e portas, que tinha de grandes lavores e fremosas madeirações ${ }^{47}$ para o seu próprio uso pessoal visto terem as suas casas destruídas.

3. Somadas todas estas despesas, o aparelho financeiro português no Oriente apresenta uma despesa de 9450 pardaus de tangas ${ }^{48}$, ou seja, cerca de 2.835 .000 reais, o que corresponde a cerca de $37 \%$ do custo de uma nau e da respectiva carga na carreira da Índia, à partida de Lisboa (orçado em cerca de 7,6 milhões de réis) ou, se se preferir, a 4\% dos lucros anuais obtidos pela Rota do Cabo (aproximadamente 72 milhões de réis em 1534) ${ }^{49}$. A feitoria de Diu arcou com a maior parte dos gastos, exceptuando os reforços e materiais enviados de Goa, Chaul e Baçaim, de onde eram pagos um ou dois meses adiantados.

No entanto, aquando do início das obras, em final de Novembro, o governador não possuía os meios financeiros necessários para cobrir as despesas que se anteviam - em parte por ter gasto uma soma considerável em mercês concedidas aos soldados e fidalgos portugueses ${ }^{50}$. Pediu então um empréstimo à cidade de Goa, no valor de vinte mil pardaus de tanga, alegando a necessidade de reconstruir a fortaleza, salientando as «[...] grandes opressões e contínuos achaques que me dão os lascarins por paga, de que lhes dou muita certeza porque doutra maneira se me irião todos, e ficarei só nesta fortaleza $\rangle^{51}$. Para reforçar a sua própria palavra, D. João de Castro enviava como penhor alguns pêlos da sua própria barba ${ }^{52}$. A ideia inical passava pelo envio dos ossos do filho, D. Fernando de Castro, morto durante o cerco, no entanto «[...] acharão-no de tal maneira que não foi licito ainda agora de o tirar da terra $\aleph^{53}$. Era o próprio governador que afirmava que não

${ }^{47}$ Idem, ibidem.

${ }^{48}$ Caderno das Despesas, fl. 235r.

${ }^{49}$ Cf. COSTA, Leonor Freire e LAINS, Pedro e MIRANDA, Susana Münch - História Económica de Portugal. 1143-2010. Lisboa: Esfera dos Livros, 2011, p. 117.

${ }^{50}$ CASTRO, D. Fernando de - Crónica do Vice-Rei D. João de Castro, cit., p. 343.

${ }^{51}$ ANDRADE, Jacinto Freire de - Vida de Dom João de Castro, quarto vizo-rei da India. Lisboa: Na Officina Craesbeeckiana, 1651, fl. 308.

${ }^{52}$ Que Leonardo Nunes afirma ter visto «[...] na maão de Dioguo Roiz d'Azevedo, que mas mostrou atadas num lenço»- Crónica de Dom João de Castro, cit., p. 136.

${ }^{53}$ ANDRADE, Jacinto Freire de - Vida de Dom João de Castro..., cit., fl. 309. 
possuía ouro, prata, ou bem de raiz ou móvel, «[...] somente huma verdade secca e breve que me Nosso Senhor deo» ${ }^{54}$. Em troca deste empréstimo, o Forte Castro (como lhe chamaria Camões) entregava os rendimentos do comércio dos cavalos em Goa como forma de pagamento.

Em resposta, a cidade mobilizou-se, angariando 20.146 pardaus (de tanga) e uma tanga, dos quais a própria Câmara, em carta ao governador, identifica terem sido dados pelos «[...] cidadãos e o povo, e asy os bramenes, mercadores, gamcares e ouryves $»{ }^{55}$, tendo sido reunidos 9200 e tantos pardaus pelos gemtios, e feito um livro de registo das pessoas que contribuíram para o empréstimo ${ }^{56}$. Não obstante o penhor e a oferta de pagamento feita por D. João de Castro, a cidade mostrou-se solidária, recusando as ofertas e devolvendo as famosas barbas num cofre guarnecido de prata ${ }^{57}$.

Apesar do esforço realizado pelos goeses, o montante reunido não foi utilizado. Tal se deveu a uma nau do Sultão de Cambaia, capturada ao largo de Diu por António Moniz e com um valor de 20.000 pardaus $^{58}$, dinheiro então utilizado pelo governador para as necessidades das obras. O empréstimo colectado em Goa foi consequentemente reenviado quando chegou à fortaleza, visto já não ser necessário ${ }^{59}$.

${ }^{54}$ Idem, ibidem.

${ }^{55}$ São Luís, Francisco de - Obras Completas do Cardeal Saraiva. Lisboa: Imprensa Nacional, 1876, tomo VI, p. 261. Esta carta ( $\left.\mathrm{N}^{\mathrm{o}} 35\right)$, conjuntamente com outras, foram publicadas pelo Cardeal Saraiva na reedição da obra de Jacinto Freire de Andrade, dedicada à vida de D. João de Castro, datada de 1835 (p. 460-466). Encontravam-se numa colecção adquirida pela dita personalidade, sendo confiada ao conselheiro António José Marques Correia Caldeira após a sua morte, vindo posteriormente a integrar o acervo da Torre do Tombo, conforme se pode ler na descrição do fundo hoje existente, denominado "Cartas a D. João de Castro".

${ }^{56}$ Rui Gonçalves de Caminha e o gentio Dadagi confirmam este valor: Carta de Rui Gonçalves de Caminha para D. João de Castro, datada de 28 de Dezembro de 1546 publicada in Obras Completas de D. João de Castro, cit., p. 327 e Carta de Dadagi para D. João de Castro, datada do mesmo dia in ob. cit., vol. IV, p. 44.

${ }^{57}$ COUTO, Diogo do - Da Ásia, cit., ob. cit., p. 300.

${ }^{58}$ NUNES, Leonardo - Crónica de Dom João de Castro, cit., p. 142-143. Gaspar Correia refere que o montante seria de 50 mil xerafins de ouro - Lendas da Índia, p. 585.

${ }^{59}$ Ob. cit., p. 143. Esta informação é confirmada numa carta da Câmara de Goa para D. João de Castro, datada de 7 de Janeiro de 1547: «O veador da fazenda Symão Botelho nos dixe na mesa desta Camara como vosa senhoria mandava que o denheiro do emprestemo se tornase as pessoas que o emprestaram com muitas palavras d'agradecimentos e de muita omra da cidade porque beigamos as maos a Vossa Senhoria" - ANTT, Cartas de Goa a D. João de Castro, fl. 47r. Na biografia escrita pelo neto, e em jeito laudatório, é dito que o 
A necessidade do empréstimo ilustra perfeitamente a situação económicofinanceira do Estado da Índia. Esta falta de meios não é somente fruto da economia de mercês reinante, culpada pelas largas graças concedidas depois do cerco, mas também do conturbado período em análise. Não esqueçamos que Magalhães Godinho observa uma viragem estrutural entre 1545-1552, fruto de uma profunda crise que se faz sentir na Europa e se repercute no Império Atlântico e Oriental ${ }^{60}$. Deste modo impõe-se finalmente a questão: as despesas da reconstrução da fortaleza de Diu traduziram-se num gasto acrescido para a máquina administrativa portuguesa no Oriente? Pelo que acabámos de ver podemos afirmar que não. A utilização das riquezas apreendidas às diversas naus vindas de Meca (em especial a pertencente ao sultão do Guzarate) veio aligeirar consideravelmente o alcance destes gastos.

O neto-biógrafo do Governador mostra o espanto dos feitores perante a aparente pequena despesa das obras, parecendo que tirara a D. João de Castro «[...] muita parte da reputação, porque uma cousa e outra foi muito grande e estranha novidade para aquela terra e para esta outra, pois vemos quanto dinheiro se gasta no fazer das fortalezas quando o gasto corre pelas mãos dos feitores e almoxarifes $\rangle^{61}$. As largas mercês concedidas pelo Governador aos homens que estiveram presentes no cerco e na batalha de 10 de Novembro ajudam-nos a perspectivar, também, o valor dos gastos. Vejamos: Lourenço Pires de Távora, capitão-mor da armada do reino, recebeu 2000 pardaus de tanga por se ter juntado à armada de socorro ${ }^{62}$; D. João de Mascarenhas, capitão da fortaleza durante o cerco, a quem foram atribuídos 1000 pardaus pelos gastos que teve durante este assédio ${ }^{63}$; ao próprio filho, D. Álvaro de

governador afirmara que «[...] não fora à Índia buscar dinheiro nem riquezas senão honra e fama perpétua» - CASTRO, D. Fernando de - Crónica do Vice-Rei D. João de Castro, cit., p. 350.

${ }^{60} \mathrm{Cf}$. GODINHO, Vitorino Magalhães - «Flutuações económicas e devir estrutural do Século XV ao Século XVII» in Ensaios e estudos. Uma maneira de pensar. Lisboa: Sá da Costa Editora, 2009, vol. I, p. 328-329, 342-343.

${ }^{61}$ CASTRO, D. Fernando - Crónica do Vice-Rei D. João de Castro, cit., p. 343.

${ }^{62}$ BAIÃO, António - História Quinhentista (inédita)..., cit., p. 296. Esta referência, bem como as seguintes, fazem parte do Livro de Mercês que fes o Senhor Dom João de Castro sendo Visorey da India, aos capitais [sic], fidalgos daquele estado, e a todas as pessoas que o ajudarão no cerco e socorro da fortaleza de Diu, existente na Biblioteca da Ajuda (Lisboa), Códice 51-VII-8, estudado por Luís de Albuquerque em Alguns Casos da Índia Portuguesa no Tempo de D. João de Castro (I). Lisboa: Publicações Alfa, 1989.

${ }^{63}$ Ob. cit., p. 318. 
Castro, foram dados 500 pardaus, para ajuda dos gastos de ter dado mesa a alguns soldados ${ }^{64}$. Somadas todas as mercês concedidas a estes homens, ultrapassaríamos certamente o montante gasto na reconstrução da fortaleza.

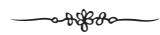

Procurámos ao longo desta leitura da documentação compreender que despesas e valores, quais os materiais e qual a gestão que D. João de Castro imprimiu às referidas obras, em colaboração com Mestre Francisco Pires e D. João de Mascarenhas. Os trabalhos de reedificação decorreram num espaço profundamente alterado e marcado por seis longos meses e meio de um cerco que marcaria definitivamente o imaginário português da presença portuguesa na Índia. Diu, centro nevrálgico do Índico português, manter-se-ia sob o domínio luso, no momento em que o eixo do Império começava a mostrar sinais da sua mudança para o Atlântico. Na sua crónica dedicada ao governador, Leonardo Nunes concluía o assunto da construção da fortaleza afirmando que Castro muitas vezes declarara que esta não custara mais que dez mil pardaus a reconstruir, acrescentando: «E vio eu per certidões dos oficiaes que as podiam dar do negoçio» ${ }^{65}$. Por felizes circunstâncias a documentação subsiste, e também nós o confirmamos, observando as mesmas certidões que este autor viu, mais de quatro séculos e meio volvidos sobre este feito de armas da gesta portuguesa no Oriente.

\section{Anexo Documental}

O presente documento encontra-se entre os fólios 234 e 244 do Códice 51-VII-19 - «Índia Portugueza, tomo I, 1542-1548», da Biblioteca da Ajuda, códice factício que reúne documentação relativa à governação da Índia de D. João de Castro (1545-1548). O documento, em papel (deixando por vezes trespassar a tinta), encontra-se em bom estado de conservação, tendo sido escrito pela mão de António Pessoa, em letra cursiva típica do século XVI.

\footnotetext{
${ }^{64}$ Ob. cit., p. 323.

${ }^{65}$ NUNES, Leonardo - Crónica de Dom João de Castro, cit., p. 146.
} 
As anotações posteriores são raras, surgindo apenas no início como forma de identificação do documento.

Ao contrário de outras fontes de carácter financeiro, os registos das despesas (apresentadas em numeração romana) não recorrem ao uso de colunas para referir as quantias, deixando um espaço em branco equivalente a três ou quatro linhas por baixo do início de cada parágrafo onde são indicadas. No final de cada página é apresentada a soma correspondente às despesas aí registadas, usando sistematicamente a numeração árabe informação que decidimos colocar em nota de rodapé.

Quanto às normas de transcrição, seguimos basicamente as propostas por Avelino de Jesus da Costa ${ }^{66}$. Procurámos respeitar o texto, sem nada lhe acrescentar, suprimir ou alterar mas, tornando-o inteligível, da seguinte forma:

- Desdobraram-se as abreviaturas sem assinalar as letras que lhes correspondem;

- Actualizou-se o uso de maiúsculas e minúsculas, do $i$ e do $j$, do $u$ e do $v$, conforme eram vogais ou consoantes;

- Ignoraram-se alguns sinais de pontuação colocados no texto, e inseriram-se outros para tornar o documento mais compreensível;

- As leituras duvidosas foram seguidas de (?);

- Os acentos foram introduzidos apenas para evitar erros de pronúncia ou interpretação;

- Separaram-se as palavras incorrectamente juntas e uniram-se os elementos dispersos da mesma palavra;

- Mantiveram-se as consoantes e vogais duplas insertas no meio do vocábulo, reduzindo-as a uma só quando no início da palavra;

- As palavras proclíticas e aglutinadas foram separadas por apóstrofo.

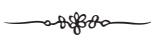

${ }^{66}$ Normas gerais de transcrição e publicação de documentos e textos medievais e modernos, $3^{\text {a }}$ ed.Coimbra: FLUC/IPD, 1993. 
1547 ABRIL 16 - Caderno das despesas realizadas na reconstrução da fortaleza de Diu, entre Novembro de 1546 e Abril de 1547.

A) Biblioteca da Ajuda (Lisboa), Cód. 51-VII-19, Índia Portugueza, tomo I, 1542-1548, fls. 234-244.

[fl. 234r] Caderno das despesas que se fizerão no fazimemto da fortaleza de Dio que o senhor governador Dom João de Crastro fez de novo que foy começada a XXII dias de Novembro de $\overline{\mathrm{I}} \mathrm{b}^{\mathrm{c}} \mathrm{RbI}$ e a acabou a Xb d'Abryll de İbcRbII. ${ }^{67}$

[fl. 235r]

$$
\dagger^{68}
$$

Mostra se valerem as despesas que forão feitas no fazimento da fortaleza de Dio que o senhor governador dom João de Crastro fez de novo per fora da fortaleza e cava que tinha damtes e com as igrejas e cassas do capytão que mandou concertaar dentro na fortaleza por estarem derrybadas da batarya e cerquo que teve e em outras obras myudas nove myll quatrocemtos e cymquoemta ${ }^{69}$ pardaos de tamgas per esta maneira abaixo e ao diamte decrarado.

Item IXcLXXbI pardaos IIII tangas de 5 tangas o pardao que foram pagos d'amte mao a II'RI pessoas pedreiros e cabouqueiros e ferreiros carpimteiros gemte da terra e portugeses que foram de Goa com o senhor governador per seu mandado paguos de II meses d'amte mão per esta maneira scilicet IIII ${ }^{c}$ pardaos a cem cabouqueyros a rezao de II pardaos de tamgas a cada hum por mes, Item IIII ${ }^{c} \mathrm{RbIII}$ pardaos que foram pagos a CXII pedreiros do dito tempo e ha dita rezao, Item XXX pardaos a b mocadoes do dito tempo a rezao de III ${ }^{c}$ pardaos a cada hum por mes, Item LIIII pardaos a XII carpimteiros tambem homens da terra emtrando hum mocadão, os carpimteiros a rezão de II pardaos a cada hum e 1 mocadão a III pardaos, Item XbI pardaos a

${ }^{67}$ No topo, em letra mais recente $« 1547 »$, bem como na margem direita, paralelo ao texto «Dio»e por baixo «21 Novembro 46, 16 Abril 47».

${ }^{68}$ No topo, em letra mais recente «1547», bem como no canto superior direito encontra-se «Da reedificação da fortaleza de Dio feita por D. João de Castro pola J. Freire na sua Vida, Liv. 3, $\mathrm{N}^{\circ} 29$ e 31» - referência à obra seiscentista de Jacinto Freire de Andrade, Vida de Dom Joao de Castro quarto Viso-Rey da India.

${ }^{69} \mathrm{Na}$ margem direita: «IX $\mathrm{IIII}{ }^{\mathrm{C}} \mathrm{L}$ pardaos». 
bIII mocos fereiros da terra dos ditos II meses a rezao de $\mathrm{b}$ tamgas a cada hum, Item XX bIII pardaos IIII tamgas que forão pagos a IIII pedreiros portugeses $\operatorname{dos}^{70}$ [fl. 235v] ditos meses a rezao de II bimtens por dia a cada hum a qual despesa foy feita d'amte mão por Pero Lopez de Samde feitor de Goa como parece per sua certidão ${ }^{71}$.

Item CLXX pardaos II'RbIII reas que vall o mamtimento que foy dado em Goa per o tempo de hum mes a II ${ }^{c}$ XXXI pessoas scilicet cabouqueiros pedreiros ferreiros e a carapimteiros gente da terra e alguns portuges per esta maneira scilicet XXbIII pardaos LRb reas que valem bIII quintais I aroba XXIIII arates de bizcouto que se deu pera LXXII pedreiros cabouqueiros christaos da terra a rezao de IX $^{\mathrm{c}}$ reas o quintal, Item XXbIII pardaos III tamgas que vallem bI candis X maos XXX mididas d'aroz giracal que lhe foy dado a rezam de XXII tamgas o candil, Item RbII pardaos II tamgas que valem XIII camdis II maos XXI mididas d'aroz preto a rezao de XbIII tamgas o candil pera $\mathrm{CRb}$ pedreiros e cavouqueiros canaris, Item IIII pardaos LXbII reas que val I quintal I aroba XX arates de bizcouto pera mantimentos de XII carpimteiros christaos, Item IIII pardaos CLR reas de I candil I mão $\mathrm{XXb}$ medidas d'aroz giracaal que foy dados aos ditos XII carpimteiros, Item RbII pardaos II tamgas que foram dados a II $\mathrm{XXXbII} \mathrm{pessoas} \mathrm{da} \mathrm{terra} \mathrm{pera}$ pescado a rezão de hũa tamga a cada hum pera o dito mes, Item II pardaos CLRbI reas que valem XIIII maos XbIII medidas d'aroz que ${ }^{72}$ [fl. 236r] forao dados a bIII mocos ferreiros da terra que entra no comto da comtia atras decrarado, Item os bII pardaos III tamgas que val o mamtimento que foy dado de bizcouto carne e pescado e manteiga e aroz que foy dado a IIII pedreiros portugeses pera tempo de hum mes segundo ordenança, os quaes mantimentos receberam em Fernam Nuniz almoxarife dos mantimentos de Goa pera o dito mes começado em XIX de Setembro de 546 em deamte que he o tempo que partirao pera Dio per mandado do senhor governador.

Item $\mathrm{X}$ pardaos que se deu de lenha pera se fazer de comer a toda esta gente

\footnotetext{
${ }^{70}$ No canto inferior direito «Soma 976 pardaos 4 tamgas».

${ }^{71}$ Certidão de Goa, fls. 248r e 257v. Todas as certidões referidas no documento encontram-se anexadas, no mesmo códice.

${ }^{72}$ No canto inferior direito «Soma 170 pardaos 248 reas».
} 
Item LXXXbIII pardaos IIII tangas que val o mamtimento que foy dado em Baçaim per mandado do vedor da fazenda que pera yso levarão dele de Goa has ditas II ${ }^{c}$ RI pessoas atras decrarados scilicet XXXIII pardaos IIII tamgas de XXIIII candis II paras d'aroz a rezão de bII tamgas o candil que he o preço que laa valia que montou a $\mathrm{II}^{\mathrm{c}} \mathrm{XXXbII}$ pessoas da terra, Item RbII pardaos II tamgas pera pescado ha dita gente a rezao de hũa tanga a cada hum por mes, Item os bII pardaos III tamgas que val o mamtimento de bizcouto aroz e mamteiga e carne e pescado pera os IIII pedreiros portugeses o qual mamtimento lhe foy dado pera hum mes como dito he acabado a XIX de Novembro de $546^{73}$.

[fl. 236v] Item b'RIIII pardaos de tamgas per IIII'LIII pardaos d'ouro II tamgas que foram pagos em Dio pelo feytor Amtonio Gil a CXXX pedreiros e cavouqueiros a rezão de dous pardaos de tamga a cada hum por mes e a quatro mocadõees a rezão de III pardaos por mes, pagos de dous meses começados a XIX de Novembro de 546 the XIX de Janeiro de 547 e os ditos pardaos d'ouro foram despesas a rezao de bI tamgas cada hum posto que em Dio valesem a $b$ tamgas a qual despesa foy feita pelo dito feitor como se parece per sua certidão ${ }^{74}$.

Item $\mathrm{LXb}$ pardaos IIII tamgas que val o mamtimento que foy dado em Dio aos ditos CXXX pedreiros e cavouqueiros e a IIII mocadoes em tempo dos ditos dous meses acabados a XIX de Janeiro de 547 per esta maneira scilicet XXbI pardaos II tamgas de XXbI candis bI maos d'aroz a rezao de $\mathrm{b}$ tamgas o candil por asy valer na terra, Item XII pardaos III tamgas de LXIII canadas de manteyga a rezao de hum quartilho por dia a cada pedreiro por asy ordenaar o senhor governador pelo muito trabalho que tinhão nas obras da dita fortaleza, Item XXbI pardaos IIII tamgas de pescado a rezao de mea tamga a cada hum por mes que valia o que lhe foy dado pelo aver na terra ${ }^{75}$.

[fl. 237r] Item CbIII pardaos de tamgas per LR pardaos d'ouro que foram pagos pelo dito Amtonio Gil a XXbII pedreiros que forao doentes

\footnotetext{
${ }^{73}$ No canto inferior direito «Soma 98 pardaos 4 tangas».

${ }^{74}$ «Lembrança dos pagamentos...», feita pelo dito feitor de Diu, António Gil, no mesmo códice, fls. 258r.

${ }^{75}$ No canto inferior direito «Soma 609 pardaos 4 tamgas».
} 
pera Goa pagos dos ditos dous meses atras decrarados como se parece pela dita certidão do dito feitor de $\mathrm{Dio}^{76}$.

Item $\mathrm{RbIII}$ pardaos de tamgas per $\mathrm{R}$ pardaos d'ouro que foram pagos pelo dito Amtonio Gil feitor de Dio a XII carpinteiros da terra christaos pagos dos ditos dous meses a rezao de dous pardaos de tamgas a cada hum como se parece pela dita çertidão ${ }^{77}$.

Item XXIIII pardaos de tamgas per XX pardaos d'ouro que foram pagos a Francisco de Resende mestre das obras da carpentaria de soldo de III moços officiaes de tempo de IIII meses começados em primeiro de Dezembro de 546 the fim de Março de 547 a rezao de dous pardaos a cada hum por mes pagos pelo dito feitor Amtonio Gil como se parece per sua certidão ${ }^{78}$.

Item I pardao IIII tamgas d'aroz e pescado aos ditos moços do dito tempo $^{79}$.

[fl. 237v] Item $\mathrm{bI}^{\mathrm{c}} \mathrm{Rb}$ pardaos de tamgas per $\mathrm{b}^{\mathrm{c}} \mathrm{XXXbII}$ pardaos e meo d'ouro a rezao de bI tamgas o pardao que mais foram pagos pelo dito feitor Amtonio Gil em Dio a CXXIII pedreiros e cavouqueiros e a quatro mocadoes ha dita dita rezao atras decrarada de tempo de dous meses e meo acabados no tempo que ho senhor governador partio de Dio pera Goa como se parece pela dita çertidam do dito feitor ${ }^{80}$.

Item LXXXII pardaos III $1 / 2$ tamgas que val o mantimento que foy dado aos ditos CXXIII pedreiros e cavouqueiros e IIII mocadoes de tempo de dous meses e meo te a partida do senhor governador de Dio pera Goa per esta maneira scilicet XXXIII $1 / 2$ pardaos de XXXIII candis e meo d'aroz a rezao de $b$ tamgas o candil, Item XXXI pardaos III $3 / 4$ tamgas de pescado pera o dito tempo a rezao de mea tamga a cada hum por mes, Item os XbII pardaos IIII $1 / 2$ tamgas de LXXIX canadas e hum quartilho de manteiga a rezao de hua tamga cada canada.

Item R pardaos de tamgas per XXXIII pardaos d'ouro II tamgas que foram pagos em Dio pelo feitor Amtonio Gil a ${ }^{81}$ [fl. 238r] bIII carpinteiros

\footnotetext{
76 «Lembrança dos pagamentos...», fl. 258r.

${ }^{77}$ Idem, ibidem.

${ }^{78}$ Idem, fl. $258 \mathrm{v}$.

${ }^{79}$ No canto inferior direito «Soma 181 pardaos 4 tamgas».

${ }^{80}$ «Lembrança dos pagamentos...», fl. 258v.

${ }^{81}$ No canto inferior direito «Soma 767 pardaos $3 \frac{1}{2}$ tamgas»
} 
de tempo dos ditos II $1 / 2$ meses acabados no tempo atras decrarado como outrosy parece pela dita certidam do dito feitor ${ }^{82}$.

Item IIII pardaos de tamgas que val o aroz e pescado que foy dado aos ditos bIII carpinteiros dos ditos II meses meo.

Item XXXbII pardaos de tamgas per XXX pardaos d'ouro e $b$ tamgas que foram pagos pelo dito feitor Amtonio Gil em Dio de tempo de dous meses começados em primeiro de Dezembro de 546 te fim de Janeiro de 547 a rezão de bII tamgas meo a cada hum por mes como se parece pela dita certidam do dito feitor ${ }^{83}$.

Item IIII pardaos II tamgas que val o aroz e pescado que foy dado em Dio aos ditos XI fereiros acyma decrarados dos ditos II meses te fim de Janeiro de 547.

Item XXXbIII pardaos IIII tamgas que foram pagos em Dio pelo dito feitor Amtonio Gil a X ferreiros dos XI acima decrarados de tempo de II meses meo do primeiro de Fevereiro de 547 te $\mathrm{Xb}$ d'Abril do dito ano ha dita rezam como se contem na dita certidão ${ }^{84}$

[fl. 238v] Item b pardaos de tamgas que val o mantimento d'aroz e pescado que foy dado aos ditos $\mathrm{X}$ fereiros atras decrarados e tempo de II meses e meo te $\mathrm{Xb}$ d'Abril do dito anno a rezão de b tamgas o candil como val na terra.

Item XXXIX xerafis I tamga que foram pagos em Chaul per Antonio Ribeiro feitor a XII cavouqueiros e II mocadoes per esta maneira scilicet bIII pardaos aos ditos II mocadoes e XXIIII pardaos aos XII cavouqueiros e os bII pardaos I tamga que lhe mais pagou pera leixarem suas molheres pagos de tempo de hum mes de $\mathrm{Xb}$ d'Outubro de 546 em diamte como se parece per certidam do dito feitor Amtonio Ribeiro ${ }^{85}$.

Item XXX pardaos de tamgas que foram pagos pelo dito Amtonio Ribeiro em Chaul a $X$ pedreiros de tempo de hum mes começados a Xb d'Outubro de 546 em diamte a rezao de III pardaos a cada hum por mes.

\footnotetext{
82 «Lembrança dos pagamentos...», fl. 258v.

${ }^{83}$ Idem, ibidem.

${ }^{84}$ Idem, ibidem. No canto inferior direito «Soma 84 pardaos I tamga».

${ }^{85}$ Certidão de Chaul, fls. 252-253.
} 
Item RIII pardaos de tamgas per $\mathrm{XXXb}$ pardaos d'ouro e $\mathrm{b}$ tamgas que foram pagos em Dio per Amtonio Gil feitor ${ }^{86}$ [fl. 239r] de Dio a XXII pedreiros de Chaul com o mocadao de tempo de hum mes começados em bII de Novembro de 546 em diamte a rezao de dous pardaos a cada hum ao mocadam a tres como se parece per certidão do dito Amtonio Gil ${ }^{87}$.

Item $\mathrm{b}$ pardaos meo que val o mantimento d'aroz pescado e manteiga que foy dado em Dio a estes XXII cavouqueiros pera tempo de hum mes.

Item LXXX pardaos IIII tamgas per LXbII pardaos d'ouro II tamgas que mais foram pagos pelo dito Amtonio Gil a XX pedreiros de Chaul com o mocadao de tempo de II meses começados em bII de Dezembro de 546 the bII de Fevereiro de 547 a rezao de dous pardaos a cada hum e o mocadão a tres por mes como se parece pela dita çertidão ${ }^{88}$.

Item bIII pardaos I tamga que val o mantimento d'aroz manteyga e pescado que foy dado em Dio aos ditos XX pedreiros de tempo dos ditos II meses. ${ }^{89}$

[fl. 239v] Item LXXXIX pardaos II tamgas que foram pagos mais pelo dito Antonio Gil feitor de Dio a XXIII pedreiros e hum cherqua (?) de tempo de II meses começados em bII de Fevereiro de 547 the bII d'Abril do dito anno ha dita rezao atras decraradas como se parece pela dita çertidam ${ }^{90}$.

Item XII pardaos que val o mantimento d'aroz manteiga e pescado que foy dado em Dio pera os ditos pedreiros nos ditos dous meses.

Item $\mathrm{XXXb}$ pardaos de tamgas que foram pagos em Chaul pelo feitor Antonio Ribeiro a XXXIII bigaris e hum mocadam que mandou a Dio de tempo de hum mes começados a b de Dezembro de 546 em diamte como se parece per sua çertidão ${ }^{91}$.

Item bII pardaos que val o mantimento d'aroz e pescado que foy dado em Dio pera estes XXXIII bigaris e hum mocadão pera tempo de hum mes começados a bIII de Dezembro de 546 em diamte. ${ }^{92}$

\footnotetext{
${ }^{86}$ No canto inferior direito «Soma 117 pardaos I tamga».

${ }^{87}$ «Lembrança dos pagamentos...», fl. 259r.

${ }^{88}$ Idem, ibidem.

${ }^{89}$ No canto inferior direito «Soma $941 / 2$ pardaos».

${ }^{90}$ «Lembrança dos pagamentos...», fl. 259v.

${ }^{91}$ Certidão de Chaul, fls. 252-253.

${ }^{92}$ No canto inferior direito «Soma 143 pardaos 2 tamgas».
} 
[fl. 240r] Item RIII pardaos que foram pagos pelo feitor Antonio Ribeiro em Chaul a RIII bigaris que mais mandou a Dio pera tempo de hum mes começado em XXIX de Dezembro de 546 em diante como se parece pela certidão do dito feitor ${ }^{93}$.

Item IIII pardaos IIII tamgas per IIII pardaos d'ouro que foram paguos pelo dito feitor Amtonio Ribeiro em Chaul a IIII pedreiros que mais mandou a Dio pera tempo de hum mes começados em XXIX de Dezembro de 546 em diamte.

Item CII pardaos de tamgas per LXXXb pardaos d'ouro que forão pagos em Dio per Amtonio Gil feitor a XXIIII bygaris e I mocadão dos de Chaul de tempo de II meses começados em bIII de Dezembro de 546 em diamte a rezao de II pardaos a cada hum do dito tempo Item o mocadão tres como se parece per certidão do dito Amtonio Gill ${ }^{94}$.

Item bII pardaos I tanga e mea que val o mantimento que se deu aos ditos bigaris acyma decrarados d'aroz pescado e manteiga de tempo de hum mes por que d'outro mes ouveram d'antemao a chegada de Dio. ${ }^{95}$

[fl. 240v] Item CXbIII pardaos de tamgas per LRbIII pardaos d'ouro II tamgas que mais foram pagos em Dio per Amtonio Gil feitor per esta maneira scilicet LRbI pardaos a XXIIII bigarins dos de Chaul de tempo de dous meses começados a bIII de Fevereiro de 547 em diamte a rezao de dous pardaos a cada hum por mes e o mocadao III pardaos por mes de que ouve bI pardaos o dito mocadão, e os XbI pardaos a bIII bigarins de tempo de III meses começados em III de Janeiro de 547 em diamte dos quaes ouverão dous meses no feitor Amtonio Gil e hum mes no feitor Amtonio Ribeiro o qual the foy pago pelo mandar asy o senhor governador por terem muito trabalho em amasar a caal como se parece pela dita çertidão ${ }^{96}$.

Item XIIII pardaos II tamgas que val o mantimento d'aroz e pescado que foy dado a estes bigaris acima decrarados pera tempo dos ditos II meses acima decrarados.

Item XbII pardaos I tanga que foram pagos per Antonio Ribeiro feitor de Chaul a XI pedreiros e I mocadam que mais mandou ha fortaleza de Dio

\footnotetext{
${ }^{93}$ Certidão de Chaul, fls. 252-253.

${ }^{94}$ «Lembrança dos pagamentos...», fl. 259v.

${ }_{95}^{5}$ No canto inferior direito «Soma 157 pardaos mea tamga».

96 «Lembrança dos pagamentos...», fl. 259v.
} 
e ysto em começo de ${ }^{97}$ [fl. 241r] paguo do tempo que la servise a XXX de Janeiro de 547 que os de Chaul mandou como parece per sua certydam ${ }^{98}$.

Item XXIX pardaos I tamga per XXIIII pardaos d'ouro II tamgas que foram paguos em Dio per Amtonio Gil feitor a X pedreiros com o mocadao dos que foram de Chaul com Ganaa mocadam deles o qual he o conprimemto do que lhe hera devido de tempo de II meses porque o que falta lhe foy cocontado (sic) pelo que ouverão no feitor de Chaul como se vera nas outras adiçoes atras os quaes dous meses se começão de IIII de Fevereiro 547 em diamte como se parece per sua certidam ${ }^{99}$.

Item IIII pardaos IIII tamgas que val o mantimento d'aroz manteiga e pescado que se deu a estes pedreiros acima decrarados dos ditos dous meses.

Item LXXXII pardaos IIII tangas que foram pagos a III pedreiros portugeses dos que foram de Goa de tempo de IIII meses começados a XI de Novembro de 546 te XI de Marco de 547 o qual pagamento ouveram ${ }^{100}$ [fl. 241v] per esta maneira scilicet XbIII pardaos que foram pagos per Pero Lopez de Sande feitor de Goa e os LXIII pardaos IIII pardaos per LIIII pardaos d'ouro II tamgas per Antonio Gil feitor de Dio que faz a dita comtia como se parece per certidões dos ditos feitores ${ }^{101}$.

Item XIIII pardaos II tamgas per XII pardaos d'ouro que lhe mais foram pagos pelo dito Amtonio Gil pera seus almorços a rezao de hum pardao d'ouro a cada hum.

Item XbIII pardaos de tamgas que foram pagos per Joao Teixeira feitor de Baçaim a XbIII bigaris que laa mandou pera fazerem caal pera tempo de hum mes comecado a II de Dezembro 546 em diante como se parece pera sua certidam ${ }^{102}$.

Item XbI pardaos IIII tamgas per XIIII pardaos d'ouro que mais foram pagos per Amtonio Gil feitor de Dio a XIII bigaris dos que foram de Bacaim de tempo de hum mes começado em II de Janeiro de 547 em diante como se parece per certidam d'Amtonio Gil. ${ }^{103}$

\footnotetext{
${ }^{97}$ No canto inferior direito «Soma 149 pardaos 3 tamgas».

${ }^{98}$ Certidão de Chaul, fls. 252-253.

99 «Lembrança dos pagamentos...», fl. 260r.

${ }^{100}$ No canto inferior direito «Soma 116 pardaos 4 tamgas».

${ }^{101}$ «Lembrança dos pagamentos...», fl. 260r.

${ }^{102}$ Idem, ibidem.

${ }^{103}$ Idem, ibidem. No canto inferior direito «Soma 49 pardaos I tamga».
} 
[fl. 242r] Item XXI pardaos III tamgas per XbIII pardaos d'ouro que foram paguos a bII bigaris e hum mocadão de tempo de II meses começados a II de Fevereiro de 547 em diamte o qual pagamento foy feito pelo dito feitor Amtonio Gil como se vyo per sua çertidão ${ }^{104}$.

Item XI pardaos mea tamga que val o mantimento d'arooz e pescado de todo o tempo que serviram os bygaris que foram de Baçaim pera fazerem a caal.

Item İIII'LI pardaos I tamga e mea que o feitor de Baçaim Joao Teixeira despendeo em conpra de caal e despesas dela per esta maneira scilicet bI'LRIII pardaos de conpra de $\overline{\mathrm{I} I \overline{I I}} b \mathrm{I}^{\mathrm{c}} \mathrm{XX}$ candis de caal a rezao de tres quartos de tamga o candil, Item IIII' $L X X X$ pardaos de fretes de ${ }^{105}$ $\mathrm{XXbII}$ enbarcaçoes de navios fustas e cotias as quaes foy paguo calaaz de marinheiros (?) e mamtimentos e algũas frete que ha levarão a Dio, Item CX pardaos de ferias de trabalhadores que acaretaram a dita caal aos navios e a enbarcavam e a cotias que na enbarcaçam servirão, Item os LXbIII pardaos I tamga mea que ${ }^{106}[\mathrm{fl} .242 \mathrm{v}]$ valem RbIII candis XbI maos d'aroz a rezao de bII tamguas o candil que gastou no mamtimento das ditas enbarcacoes como se parece per certidam do dito feitor asynada pelo capitão dom Geronimo ${ }^{107}$.

Item $\mathrm{C}$ pardaos de tamgas que ho dito feitor podia despender em compra de $\mathrm{b}$ cestos que mandou ha dita fortaleza pera o serviço dela segundo o que ${ }^{108}$ pareceo a Symão Botelho vedor da fazenda e a Amtonio Pessoa que hos virão e mandaram gastar.

Item $\overline{\mathrm{I}} \mathrm{b}^{\mathrm{c}} \mathrm{LXXb}$ pardaos de tamgas que foram pagos por Pero Lopez de Sande feitor de Goa a b $b^{c}$ XIII bigaris entrando II mocadoes a rezao de bII tamgas mea a cada bigarys e os mocadoes a $\mathrm{Xb}$ tamgas pagos de II meses d'amtemão como se vyo per certidão do dito feitor ${ }^{109}$.

Item II ${ }^{c} X X I$ pardaos I tanga que val o mantimento que foy dado pera estes bigaris pera tempo de hum mes pera aroz e pescado que ouveram no

\footnotetext{
${ }^{104}$ «Lembrança dos pagamentos...», fl. 260v.

${ }^{105}$ Segue-se letra riscada.

${ }^{106}$ No canto inferior direito «Soma 1384 pardaos».

${ }^{107}$ Certidão de Baçaim, fls. 251 e 254.

${ }^{108}$ Encontra-se riscado a seguir «0».

${ }^{109}$ Certidão de Goa, fls. 249 e 256.
} 
almoxarife de Goa Fernam Nuniz a XbIII tamgas o candil d'aroz que valia o qual se deu segundo ordenança. ${ }^{110}$

[fl. 243r] Item CXXXbII pardaos de tamgas per CXIIII pardaos d'ouro I tamga que foram pagos per Antonio Gil feitor de Dio a CXXXI bigaris e tres mocadoes dos que foram de Goa de tempo de hum mes começado a Xb de Março de 547 em diamte como se parece por certidão do dito feitor ${ }^{111}$.

Item CLXXI pardaos de tamga que foy dado a estes officiaes abaixo decrarados halem de seu mantimentos ordinario pelo muito trabalho que tinhão per esta maneira scilicet CXX pardaos per C pardaos d'ouro a Francisco Pirez e a Afonso Madeira mestres das obras da fortaleza do tempo $\mathrm{de} \mathrm{b}$ meses a rezao de $\mathrm{X}$ pardaos d'ouro a cada hum por mes, Item $\mathrm{Xb}$ pardaos de tamgas per XII pardaos meo d'ouro a mestre Pero mestre das ferrarias dos ditos cinquo meses e a rezao de II pardaos meo d'ouro cada mes, Item bI pardaos de tamgas per b pardaos d'ouro a Gaspar Fernandez irmão do dito Mestre Pero a rezao de hum pardao d'ouro por mes dos ditos b meses, Item X pardaos de tamgas a Alvaro Pirez condestabre mor da armada por ter muito trabalho e fazer pólvora em Dio de tempo de $\mathrm{b}$ meses a rezao de $\mathrm{X}$ tamgas por mez, Item II pardaos de tamgas a Francisco de Resende mestre dos carpinteiros do tempo de hum mes, Item os XbIII pardaos de tamgas a tres pedreiros portugeses ${ }^{112}$ [fl. 243v] de tempo de b meses a rezao de hum pardao d'ouro a cada hum por mes pera seus almorços.

Item $\mathrm{C}$ pardaos de tamgas que se aquy mais faz comta de despesa de ferramentas que se podia gastar e furtar nas ditas obras da dita fortaleza.

Item CXbI pardaos III tamgas com que se comprou CLXXIII moyos de caal que se levou de Goa a Dio pera as ditas obras como se parece per certidam de Pero Lopez de Sande feitor de Goa ${ }^{113}$.

Item IIII'LIIII pardaos I porgil que despendeo Amtonio Fil feitor de Diu em XIX ferias de trabalhadores guzarates scilicet carpinteiros pedreiros cavouqueiros boys e bigaryns e mulheres que trabalharam nas ditas obras de XXIX de Novembro de 546 athe XI d'Abril de 547 que se acabarão as

\footnotetext{
${ }^{110}$ No canto inferior direito «Soma 1896 pardaos I tamga».

${ }^{111}$ «Lembrança dos pagamentos...», fl. 260v.

${ }^{112}$ No canto inferior direito «Soma 308 pardaos».

${ }^{113}$ Certidão de Goa, fls. 250 e 255 v.
} 
ditas obras e se partio o senhor governador pera Goa por ser ja acabada a dita fortaleza como se pareçe per çertidam do dito Amtonio Gil. ${ }^{114}$

[fl. 244r] Item CXbI pardaos II'XIIII reas de CXbI candins X paras d'aroz que mais despendeo com as ditas ferias a rezao de $\mathrm{b}$ tamgas o candil que he seu preço que valia na dita fortaleza.

Item CbI pardaos II ${ }^{c} \mathrm{XbIII}$ tamgas de que se aqui mais faz conta de despesa d'algũa lenha que foy de Chaul pera se fazer caal e asy algum carvão.

Item os IIII'L pardaos de tamgas que foram pagos a Antonio Gil pera contrato que com ele fez Symão Botelho vedor da fazenda per mando do senhor governador pera comçertar a see e curicheos dela em todo o que lhe comprise e casas do capitão e asy a Igreja de Samtiago e outras obras meudas de dentro da fortaleza como se no contrato contem

Soma 673 pardaos 132 reis

Noteffiquo Amtonio Pessoa como todas estas despesas comteudas neste caderno foram feytas peramte mym per mandado do senhor governador por me diso encarregar com os o[fl. 244r]fficiaes del rei noso senhor a que pertençyão faze las e as certidõees que os asemtos deste caderno requerem sam em poder de Sua Senhoria e por asy pasar em verdade asyney aquy em Goa oje XbI de Julho de 547

[assinatura] Antonio Pesoa

${ }^{114}$ «Trelado das fereas...», fls. 262-266v e 268. No canto inferior direito «Soma 1470 pardaos 3 tamgas 10 reas». 